\title{
Prediction of Intracardiac Pressures and Assessment of Ventricular Function with Doppler Echocardiography
}

\author{
A. REBECCA SNIDER, M.D. \\ C. S. Mott Children's Hospital, University of Michigan Medical Center, Ann Arbor, Michigan.
}

Doppler echocardiography provides a noninvasive technique by which blood flow in cardiac chambers and vessels can be characterized, and the timing and direction of flow can be determined. Transvalvular pressure gradients can be quantified noninvasively by Doppler echocardiography. Combined imaging and Doppler allow quantification of volume flow rates. Intracardiac pressures and cardiac function can be evaluated by combining such measurements with observations from the physical examination.

One of the most important concepts used in noninvasive estimation of intracardiac pressures is that transvalvular pressure gradients can be calculated in the presence of valvular regurgitation as well as in the presence of valvular stenosis. In both instances, the Doppler equation is used to calculate blood velocity (V) from the Doppler frequency shift (Fd) and the cosine of the Doppler angle $(\operatorname{Cos} \theta)$ :

$$
\mathrm{V}=(\mathrm{Fd}) / \operatorname{Cos} \theta)(\mathrm{K})
$$

where the constant $(\mathrm{K})$ in the Doppler equation is speed of ultrasound in tissue divided by " 2 " times the carrier frequency. The equation is further simplified in most clinical settings by aligning the ultrasound beam parallel to the high velocity vectors from the stenotic or regurgitant lesion. The cosine of the Doppler angle is then assumed to be 1 and the blood velocity is directly proportional to a constant times the Doppler frequency shift. Underestimation of true velocity is possible when using this approach.

Address for correspondence: A. Rebecca Snider, M.D., F1609, C. S. Mott Children's Hospital, University of Michigan Medical Center, Ann Arbor, MI 48109.
Pressure gradients (PG) are calculated by measuring the velocity $(\mathrm{V})$ across the valve. The simplified Bernoulli equation:

$$
\mathrm{PG}=4(\mathrm{~V})^{2}
$$

allows calculation of the pressure gradient from the blood velocity. ${ }^{1-10}$

This article reviews noninvasive quantification of intracardiac pressure and assessment of cardiac function. The Bernoulli equation is used extensively to quantify intracardiac pressures. Analysis of the timing of flow is utilized to assess intracardiac pressures as well as cardiac function.

\section{Calculation of Intracardiac Pressures}

Doppler echocardiography allows estimation of right ventricular, pulmonary artery, left ventricular, and left atrial pressures. Because estimation of pulmonary artery pressure is most useful and least prone to error, it is discussed first.

\section{Right Heart Pressures}

Because pulmonary artery and right ventricular systolic pressures are nearly equal in the absence of disease involving the right ventricular outflow tract, pulmonic valve, or supravalvular region, pulmonary artery systolic pressure is commonly estimated by techniques that measure right ventricular systolic pressure. The most common method involves using tricuspid regurgitation to calculate the right ventricularto-right atrial pressure gradient. Pulmonary artery systolic pressure can also be calculated directly by noting the timing of the peak pulmonary artery pressure. Both approaches are clinically useful.

1. Pulmonary Artery Systolic Pressure from Tricuspid Regurgitation. Doppler echocardiographic evidence of tricuspid regurgitation is 
common in patients with pulmonary hypertension, as well as in normal patients who have no physical evidence of tricuspid valve disease. ${ }^{11} \mathrm{As}$ shown in Figure 1, the Doppler signals characteristic of tricuspid regurgitation can be re-

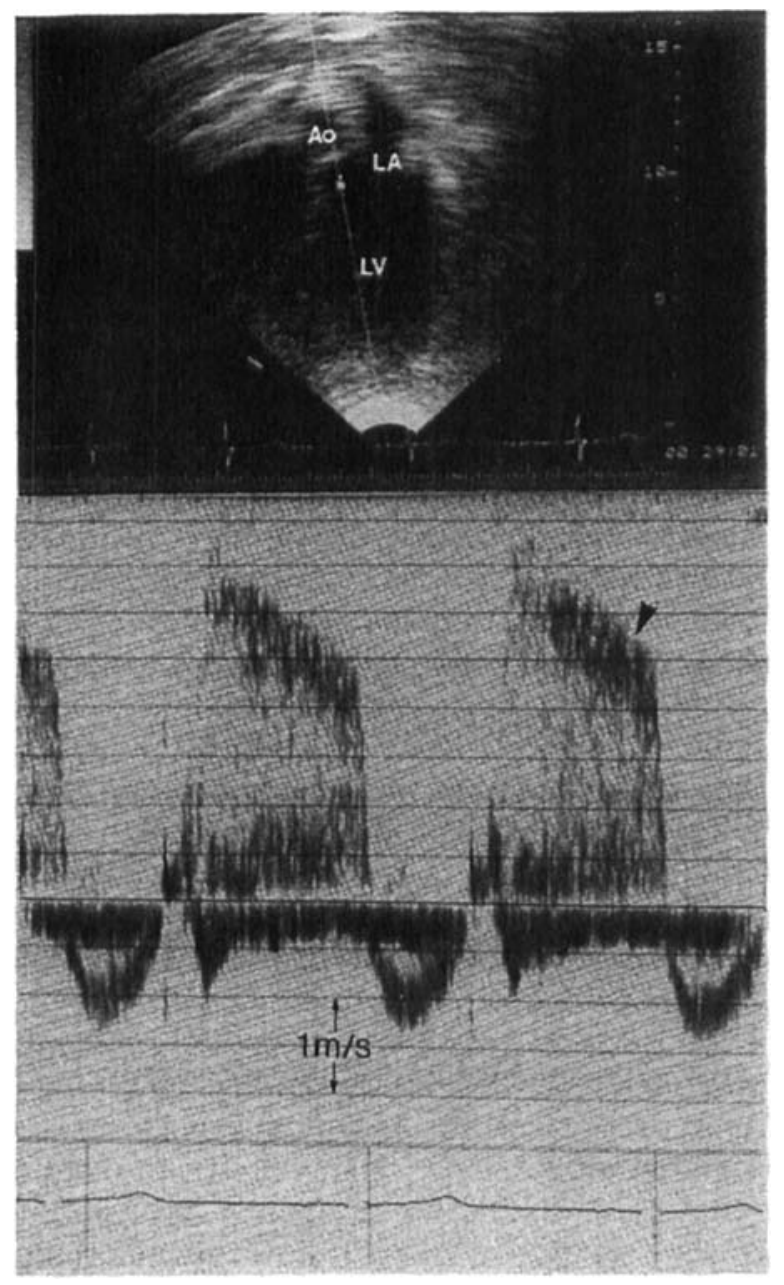

Figure 1. High pulse repetition frequency Doppler recording (bottom) from the apical four-chamber view (top) of a patient with multivalvular disease. The sample volume is positioned in the right atrium (RA) proximal to the tricuspid valve. The Doppler spectral tracing shows signals below the baseline in systole indicating flow from the right ventricle $(R V)$ to the $R A$ in systole or tricuspid insufficiency (TI). The peak velocity of the TI jet (black arrow) is $2.5 \mathrm{~m} / \mathrm{sec}$. This predicts a pressure gradient of $4 \times(2.5)^{2}$ or $25 \mathrm{~mm} \mathrm{Hg}$ between the $R A$ and $R V$ in systole. RA pressure was measured by a central venous pressure line to be $36 \mathrm{mmHg}$. Peak $R V$ systolic pressure is, therefore, $36+25$ or $61 \mathrm{mmHg}$. $L A=$ left atrium; $L V=$ left ventricle. corded by placing the transducer at the cardiac apex and obtaining a four-chamber view. The ultrasound beam is directed through the tricuspid valve and aligned parallel to the high velocity jet between the right ventricle and the right atrium. Careful adjustment of the transducer location and the ultrasound beam is essential to assure a small Doppler angle and accurate quantification of actual velocity. Pansystolic velocities from the right ventricle into the right atrium are directed away from the transducer and are thus shown on the negative side of the baseline on the spectral time-velocity recording.

The peak systolic right ventricular-to-right atrial pressure gradient ( $\mathrm{PG} / \mathrm{s}$ rv-ra) is calculated using the Bernoulli equation and peak systolic velocity of tricuspid regurgitation $(\mathrm{V} t r)$ from the Doppler ${ }^{12}$ :

$$
(\mathrm{PG} / \mathrm{s} \mathrm{rv}-\mathrm{ra})=4(\mathrm{~V} \mathrm{tr})^{2}
$$

Peak right ventricular systolic pressure $(P / s$ rv) can be estimated in the presence of tricuspid regurgitation if right atrial pressure $(\mathrm{P}$ ra) is known:

$$
(\mathrm{P} / \mathrm{s} \mathrm{rv})=4\left(\mathrm{~V} \mathrm{tr}^{2}+(\mathrm{P} \text { ra })\right.
$$

Several techniques are used to estimate right atrial pressure. If a central venous line is present, right atrial pressure can be measured directly. Physical examination allows determination of the height of the jugular venous pulses but can be inexact even in experienced hands. Data from physical exam, echocardiogram, and chest $x$-ray can be combined to determine whether right atrial pressures are normal or abnormal. An arbitrary $10 \mathrm{mmHg}$ is added to the calculated rv-ra gradient if the above mentioned parameters are normal.

In Figure 1, the Doppler signals toward the transducer during diastole represent forward flow through the tricuspid valve. The negative systolic velocities of tricuspid regurgitation peak at $2.5 \mathrm{~m} / \mathrm{sec}$ as shown by the black arrow. The systolic tricuspid valve pressure gradient is thus $4(2.5)^{2}$ or $25 \mathrm{mmHg}$. At the time of the Doppler study, right atrial pressure measured by a central venous line was $36 \mathrm{mmHg}$. Because the patient had no Doppler or physical evidence of obstruction near the pulmonic valve, the pulmonary artery systolic pressure was estimated at $25+36=61 \mathrm{mmHg}$. 


\section{DOPPLER EVALUATION OF CARDIAC PRESSURES AND VENTRICULAR FUNCTION}

In patients with Doppler evidence of tricuspid regurgitation and an absence of right ventricular outflow obstruction, pulmonary artery peak systolic pressure is calculated by adding the Doppler-derived rv-ra gradient to right atrial pressure. Using this technique, there has been excellent correlation between Doppler and invasive measurements of right ventricular and pulmonary artery systolic pressures. ${ }^{12}$

Berger et al simplified this approach by regressing the rv-ra gradient derived by Doppler against the pulmonary artery systolic pressure measured at catheterization. ${ }^{12}$ His regression equation allows direct calculation of pulmonary artery systolic pressure without determination or estimation of right atrial pressure:

$$
(\mathrm{P} / \mathrm{s} \mathrm{pa})=4.9(\mathrm{~V} \mathrm{tr})^{2}-.09 \mathrm{mmHg} .
$$

2. Pulmonary Artery Systolic Pressure from Ventricular Septal Defect. In patients with a ventricular septal defect, right ventricular systolic pressure can be estimated using a Doppler recording of the peak velocity across the septum (V vsd). Peak systolic pressure gradient between the right and left ventricle (PG/s lv - rv) is calculated using the Bernoulli equation:

$$
(\mathrm{PG} / \mathrm{s} \mathrm{lv}-\mathrm{rv})=4(\mathrm{~V} \text { vsd })^{2}
$$

If aortic stenosis is absent, then the brachial artery sphygmomanometer pressure $(\mathrm{P} / \mathrm{s} \mathrm{ba})$ is useful in estimating aortic peak systolic pressure:

$$
(\mathrm{P} / \mathrm{s} \mathrm{rv})=(\mathrm{P} / \mathrm{s} \mathrm{ba})-4(\mathrm{~V} \mathrm{vsd})^{2}
$$

If right ventricular outflow obstruction is also absent, right ventricular systolic pressure is near pulmonary artery systolic pressure. Thus, this approach allows detection of pulmonary hypertension in patients with a VSD and absence of left or right ventricular outflow tract obstruction. Using this approach, several investigators have reported excellent correlations between Doppler and catheterization-determined right ventricular systolic pressures ( $r$ $=.93-.95) .{ }^{13-14}$

Technically, the examination requires high PRF or continuous-wave Doppler capable of resolving high velocities, and parallel alignment of the velocity vectors through the septal defect and the ultrasound beam. Although multiple ultrasound windows are used to assure the smallest Doppler angle, the left parasternal and subcostal windows provide the highest Doppler frequency shifts. In general, the jet through perimembranous VSDs is directed anteriorly and to the right; therefore, the transducer is placed at the mid-left sternal border and aimed posteriorly, leftward, and inferiorly. ${ }^{13}$ Muscular VSDs are usually more easily interrogated from a subcostal or apical window. If unusual orientation of the jet is suspected, direct visualization of the jet with two-dimensional color flow imaging can be helpful to align the ultrasound beam parallel to the jet or to measure the Doppler angle.

3. Technical Problems. Both approaches require that obstruction to outflow from the right ventricle be absent. Doppler and imaging echocardiographic examination performed before quantification should eliminate this possibility. Likewise, the possibility of left ventricular outflow obstruction is easily eliminated during routine echo exam.

Both the tricuspid regurgitation and VSD methods require parallel alignment of the ultrasound beam and the high velocity jet to allow quantification of velocity and thus pressure gradient. Underestimation of true velocity is possible. Multiple ultrasound windows should be used. Color flow imaging may be useful in some cases to document parallel alignment or measure the Doppler angle.

The VSD approach adds the additional source of error of using brachial artery pressure to estimate central aortic pressure. Nonsimultaneous mesurements and the increased systolic pressure frequently noted in peripheral arteries pose additional problems.

A final problem is encountered with the VSD method. Doppler ultrasound measures the peak instantaneous pressure gradient between the left and right ventricles during systole. The difference between the peak left and right ventricular pressures is determined at catheterization. It is possible to have "no peak-to-peak gradient" at catheterization and a significant peak instantaneous gradient by Doppler. Because of differences in timing of the peak in left and right ventricular pressures, velocities of up to 
$2.5 \mathrm{~m} / \mathrm{sec}$ (and instantaneous gradients of up to $25 \mathrm{mmHg}$ ) have been reported in patients in whom catheterization suggested "nonrestrictive" VSDs. ${ }^{13}$

4. Mean and Diastolic Pulmonary Artery Pressure from Pulmonic Regurgitation. Pulmonary regurgitation can be recorded on the Doppler exam in about $40 \%$ of normal patients and in nearly all patients with pulmonary hy-
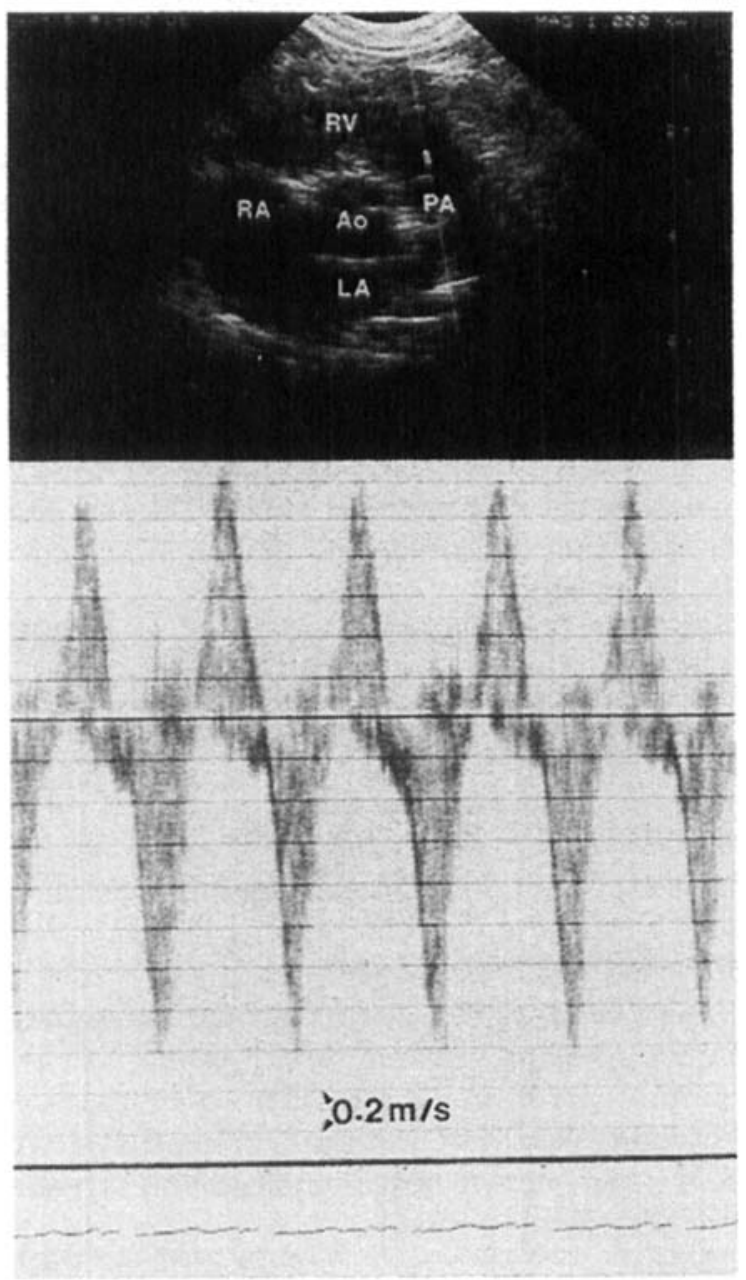

Figure 2. Pulsed-Doppler recording (bottom) from the parasternal short-axis view (top) of a patient with pulmonary insufficiency (PI). The Doppler signals above the baseline in diastole represent flow toward the transducer from the pulmonary artery $(P A)$ to the right ventricle $(R V)$ in diastole (pulmonary insufficiency). The PI signals return to the baseline at end-diastole, indicating normal $R V$ end-diastolic pressure, low PA diastolic pressure, and mild PI. Ao = aorta; $L A=$ left atrium; $R A=$ right atrium.

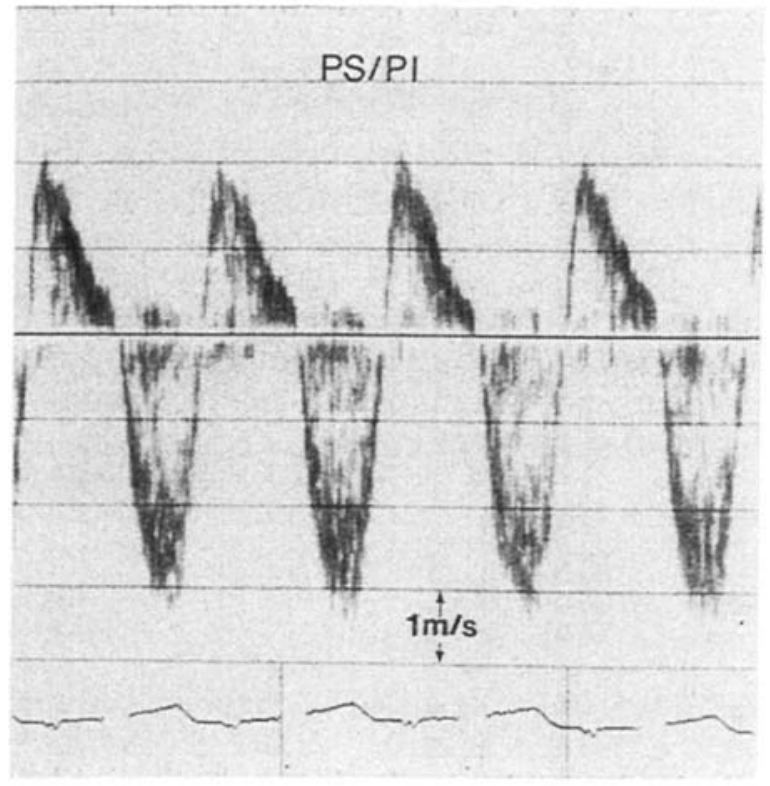

Figure 3. Continuous-wave Doppler tracing from a patient with significant pulmonary insufficiency (PI) after repair of tetralogy of Fallot and elevated right ventricular end-diastolic pressure. The Doppler signals from the PI jet return to baseline (black arrow) before the end of diastole because of equalization of right ventricular and pulmonary artery pressures in late diastole. $P S=$ pulmonary stenosis.

pertension. ${ }^{11}$ Quantification of diastolic velocities in patients with pulmonary regurgitation is helpful in calculating pulmonary artery mean and end-diastolic pressures. It should be remembered that the severity of pulmonary regurgitation, pulmonary hypertension, and right ventricular function all affect the end-diastolic pressure gradient across the pulmonary valve. In the presence of mild pulmonic regurgitation, normal right ventricular end-diastolic pressure, and low pulmonary artery diastolic pressure, pulmonic regurgitation Doppler velocities return to the baseline at end-diastole ${ }^{15}$ (Fig. 2). The low end-diastolic velocity indicates a low end-diastolic pulmonary artery to right ventricle pressure gradient. Unfortunately, as illustrated in Figure 3, low end-diastolic velocities can also be detected in patients with severe pulmonic regurgitation and elevation of right ventricular end-diastolic pressure. In individuals with elevated pulmonary artery systolic and diastolic pressures and less than severe pulmonary 
regurgitation, the end-diastolic pulmonic regurgitation remains elevated.

Despite these limitations, Masuyama and coworkers $^{16}$ showed that mean and end-diastolic pulmonary artery pressures can be calculated accurately using pulmonary regurgitant velocities. Using the Bernoulli equation and the peak pulmonary regurgitant velocity at end-diastole (V/ed pr), they calculated the diastolic pressure gradient between the pulmonary artery and the right ventricle $(\mathrm{Pg} / \mathrm{ed} \mathrm{pa-} \mathrm{rv):}$

$$
(\mathrm{PG} / \mathrm{ed} \mathrm{pa}-\mathrm{rv})=4(\mathrm{~V} / \mathrm{ed} \mathrm{pr})^{2}
$$

Comparisons between catheterization and Doppler were good $(r=.94 ; \mathrm{SEE}=3 \mathrm{mmHg})$.

Calculation of pulmonary artery diastolic pressure $(\mathrm{P} / \mathrm{ed} \mathrm{pa})$ is possible if right atrial diastolic pressure is known or estimated:

$$
(\mathrm{P} / \mathrm{ed} \mathrm{pa})=4(\mathrm{~V} / \mathrm{ed} \mathrm{pr})^{2}+(\mathrm{P} \mathrm{ra}) \text {. }
$$

A good correlation between Doppler and catheter determinations of the pulmonary arteryright ventricular end-diastolic pressure gradient has been reported..$^{16}(r=94 ; \mathrm{SEE}=3 \mathrm{mmHg})$. If

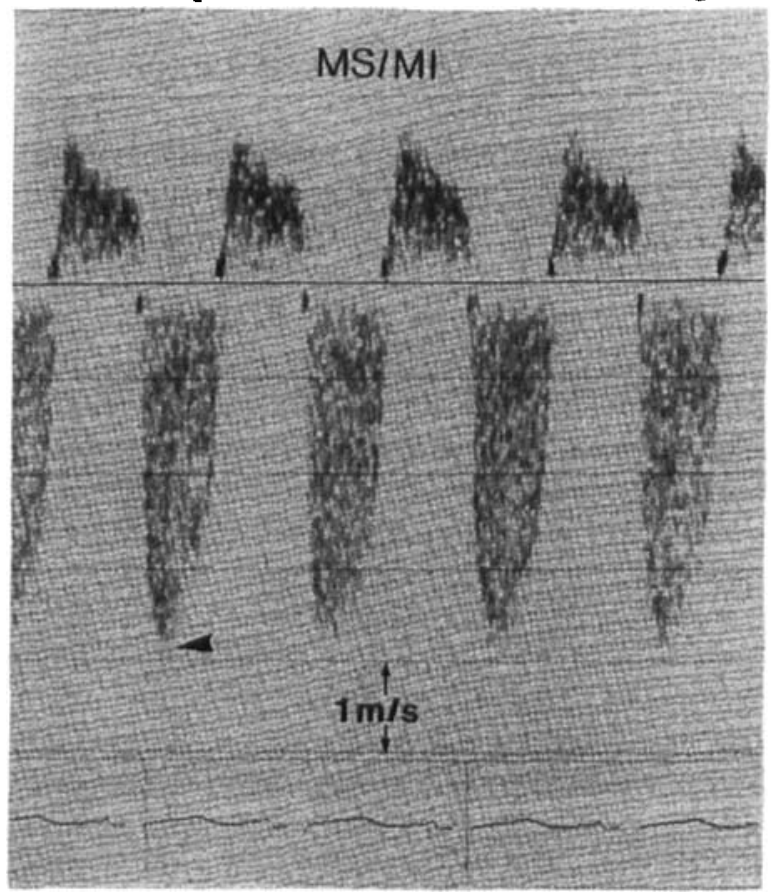

Figure 4. Continuous-wave Doppler tracing from a patient with residual pulmonary stenosis and insufficiency $(P S / P I)$ after repair of tetralogy of Fallot. The peak velocity of the insufficiency jet at end-diastole (black arrow) is $0.4 \mathrm{~m} / \mathrm{sec}$. This predicts a minimal right ventricular to pulmonary artery pressure gradient at end-diastole. right atrial or right ventricular end-diastolic pressures are unknown, pulmonary artery enddiastolic pressure can be calculated using a regression equation:

$$
4(\mathrm{~V} / \mathrm{ed} \mathrm{pr})^{2}=.61(\mathrm{P} / \mathrm{ed} \mathrm{pa})-2 .
$$

In addition, the peak velocity of the pulmonary regurgitation correlated well with mean pulmonary artery pressure $(r=.92 ; \mathrm{SEE}=5 \mathrm{mmHg})$.

In summary, if true velocity across the pulmonic valve can be determined and right atrial pressure estimated accurately, pulmonary artery end-diastolic and mean pressures can be estimated. Measurement of the true velocity requires a small Doppler angle to avoid underestimation. Inaccuracy in the measurement of right atrial pressure can lead to further difficulties.

5. Detection of Pulmonary Hypertension by Timing Pulmonary Velocities. In patients in whom tricuspid regurgitation and VSDs are absent, or in those with such pathology in whom confirmatory evidence of pulmonary hypertension is required, Doppler pulmonary artery velocity can be helpful. Hatle et $\mathrm{al}^{17}$ and Kitabatake ${ }^{18}$ have suggested that Doppler velocity tracings from the pulmonary valve orifice in patients in whom pulmonary outflow tract obstruction is absent can be used to identify patients with pulmonary hypertension. Kitabatake and associates ${ }^{18}$ noted that acceleration time (the time from onset to peak pulmonary velocity) is shortened in patients with pulmonary hypertension. In their study, patients with mean pulmonary artery pressure $<20 \mathrm{mmHg}$ had acceleration times of $137 \pm 24 \mathrm{msec}$. Those with mean pulmonary artery pressure $>20$ $\mathrm{mmHg}$ had acceleration times of $97 \pm 20 \mathrm{msec}$. The ratio of acceleration time/right ventricular ejection time correlated well with the log of the mean pulmonary artery pressure $(\mathrm{AT} / \mathrm{ET}=.45$ \pm .05 in normals and $.30 \pm .06$ in patients with pulmonary hypertension). Other studies suggest the usefulness of acceleration time alone or acceleration time/ejection time. ${ }^{19-21}$ Isobe and coworkers $^{22}$ recently noted that the ratio of right ventricular pre-ejection period ( $Q$-wave to onset of pulmonary artery flow) divided by acceleration time was the best predictor of pulmonary hypertension. Ratios $>1.1$ were found in $93 \%$ of his patients with pulmonary hypertension, 
whereas $97 \%$ of normals had ratios of $<1.1$. Since factors other than mean pulmonary artery pressure can alter the Doppler time intervals (such as age, heart rate, RV preload and function), pulmonary artery pressure based on these measurements should be interpreted with caution. $^{23}$

\section{Left Heart Pressures}

Left ventricular systolic and diastolic pressures are calculated in the presence of aortic valve disease by using systolic stenotic and diastolic regurgitant blood velocity, the Bernoulli equation, and sphygmomanometer blood pressures.

\section{Left Ventricular Systolic Pressure}

In normal patients, left ventricular systolic pressure is estimated easily by measuring brachial systolic blood pressure. In patients with aortic stenosis, left ventricular peak systolic pressure is calculated from Doppler measurement of the peak gradient across the aortic valve in systole and the simultaneous measurement of arm systolic blood pressure. Using the Bernoulli equation the aortic valve pressure gradient $(\mathrm{PG} / \mathrm{s} \mathrm{lv}-\mathrm{a})$ is determined from the peak systolic velocity across the aortic valve orifice (V as) ${ }^{1-5}$ :

$$
(\mathrm{PG} / \mathrm{s} \mathrm{lv}-\mathrm{a})=4(\mathrm{~V} \text { as })^{2}
$$

where the pressure gradient is given in $\mathrm{mmHg}$ if the velocity is shown in $\mathrm{m} / \mathrm{sec}$. Peak left ventricular systolic pressure $(\mathrm{P} / \mathrm{s} \mathrm{lv})$ is calculated by adding brachial artery systolic sphygmomanometer blood pressure ( $\mathrm{P} / \mathrm{s}$ ba):

$$
(\mathrm{P} / \mathrm{s} \mathrm{lv})=4(\mathrm{~V} \mathrm{as})^{2}+(\mathrm{P} / \mathrm{s} \mathrm{ba})
$$

Accurate determination of velocity across the stenotic orifice is essential for accurate measurement of the transvalvular pressure gradient and left ventricular systolic pressure. In clinical Doppler exams, multiple ultrasound windows (apical, right parasternal, and suprasternal) are used to assure parallel alignment of the vectors from the high velocity jet and the ultrasound beam. Using this technique, accurate estimation of such gradients is possible in children and adults with aortic stenosis. ${ }^{6-10}$

Four possible sources of error should be con- sidered. First, the pressure gradient can be underestimated if the Doppler record is obtained from a site other than the high velocity jet in the valve orifice, or if the Doppler angle is in excess of $25^{\circ}$. Second, brachial artery systolic pressure overestimates central aortic pressure. Therefore, use of brachial artery pressure, rather than central aortic pressure, would overestimate left ventricular systolic pressure. Third, the sphygmomanometer can lead to over- or underestimation of true brachial artery pressure by $5-10$ mmHg. Fourth, simultaneous measurements of brachial artery pressure and the transvalvular pressure gradient is difficult; potentially, nonsimultaneous measurements can lead to over- or underestimation of the true left ventricular systolic pressure.

\section{Left Ventricular Diastolic Pressure}

Left ventricular end-diastolic pressure can be useful in assessing left ventricular function or the severity of valvular disease. Left ventricular end-diastolic pressure can be estimated in the presence of aortic regurgitation. As shown in Figure 5, the ultrasound transducer is placed at the cardiac apex and a five-chamber view is obtained. The Doppler ultrasound beam is oriented parallel to the diastolic high velocity jet from the aorta into the left ventricle. The Doppler record shows diastolic velocities that are directed toward the transducer and decrease in a linear way from an early diastolic peak. Because left ventricular end-diastolic pressure is to be calculated, end-diastolic velocities $(\mathrm{V} / \mathrm{ed}$ ar) are used to determine the end-diastolic aortic-to-left ventricular pressure gradient (PG/ed a - lv):

$$
(\mathrm{PG} / \mathrm{ed} \mathrm{a}-\mathrm{lv})=4(\mathrm{~V} / \mathrm{ed} \mathrm{ar})^{2}
$$

Left ventricular end-diastolic pressure (P/ed lv) is calculated as the difference between brachial artery diastolic pressure $(\mathrm{P} / \mathrm{d} \mathrm{ba})$ and the aortic regurgitant end-diastolic pressure gradient:

$$
(\mathrm{P} / \mathrm{ed} \mathrm{lv})=(\mathrm{P} / \mathrm{d} \mathrm{ba})-4(\mathrm{~V} / \mathrm{ed} \mathrm{ar})^{2}
$$

Although this is a tempting way to assess left ventricular end-diastolic pressure, errors can be large. First, the very nature of the calculation tends to magnify the potential error because a 


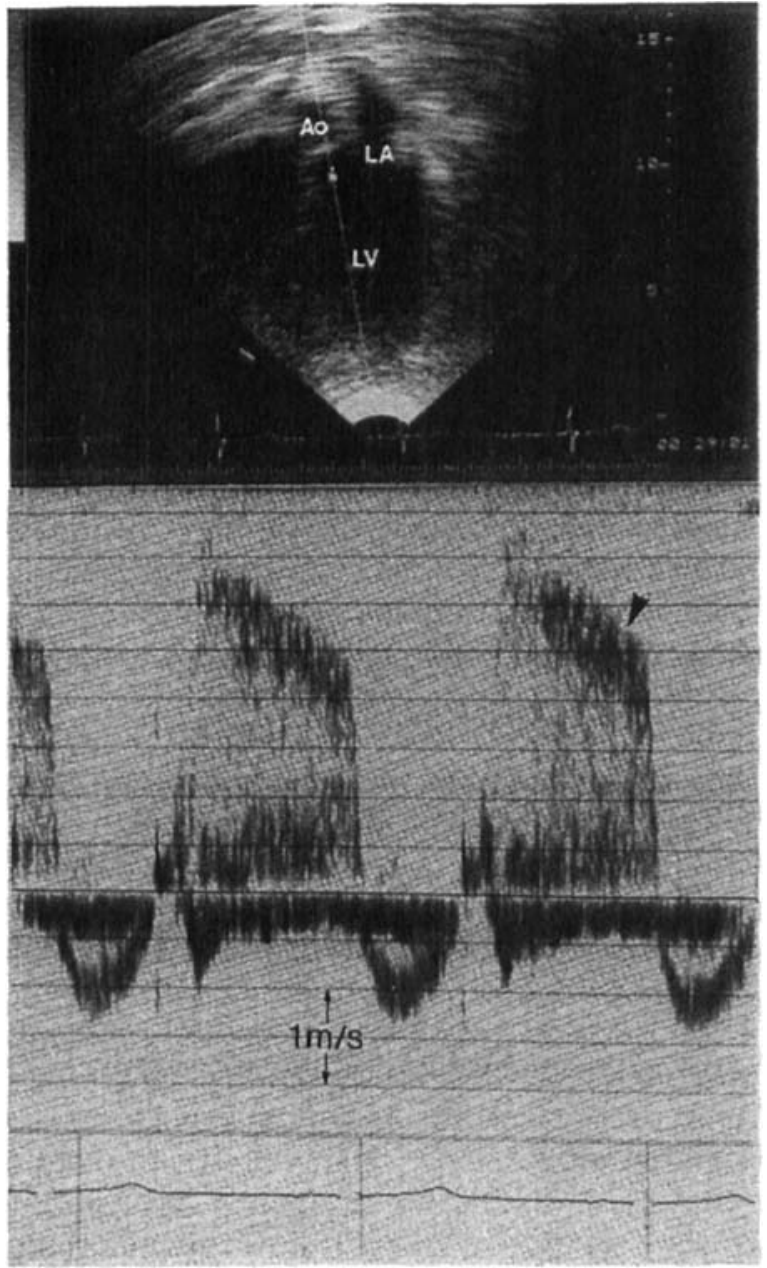

Figure 5. High pulse repetition frequency Doppler recording from the left ventricular $(L V)$ outflow tract of a patient with aortic insufficiency. The two-dimensional image of the apical view (top) shows the position of the sample volume just beneath the aortic (Ao) valve at the time of the Doppler recording. The Doppler spectral tracing (bottom) shows Doppler signals above the baseline in diastole indicating blood flow toward the transducer from the Ao to the $L V$ in diastole (aortic insufficiency). The peak velocity of the aortic insuffciency jet at end-diastole (black arrow) is $2.7 \mathrm{~m} / \mathrm{sec}$. This predicts an Ao to $L V$ pressure gradient at enddiastole of $4 \times(2.7)^{2}$ or $29 \mathrm{mmHg}$. The patient's arm diastolic blood pressure was $45 \mathrm{mmHg}$. LV end-diastolic pressure is, therefore, $45-29$ or $16 \mathrm{mmHg}$. $\mathrm{LA}$ $=$ left atrium.

relatively small number (the end-diastolic pressure) is derived by subtracting two larger numbers (brachial artery diastolic pressure from the diastolic pressure gradient). Second, the end-di- astolic velocity is moderate to high in most cases $(2.5-5.0 \mathrm{~m} / \mathrm{sec})$ and it is squared; small errors in the velocity result in large errors in the squared velocity required to calculate the gradient. Third, brachial artery diastolic pressure frequently exceeds central aortic diastolic pressure. Fourth, sphygmomanometer diastolic pressures are frequently $5-10 \mathrm{mmHg}$ different from actual brachial artery pressure. Fifth, the pressure measured and the pressure gradient calculated by Doppler are not obtained simultaneously. Despite these limitations, this approach can produce clinically useful measurements of left ventricular end-diastolic pressure in some patients.

\section{Left Atrial Pressure}

Peak systolic left atrial pressure can be calculated in patients in whom mitral regurgitation is present but aortic stenosis is absent. As seen in Figure 6, the ultrasound transducer is placed

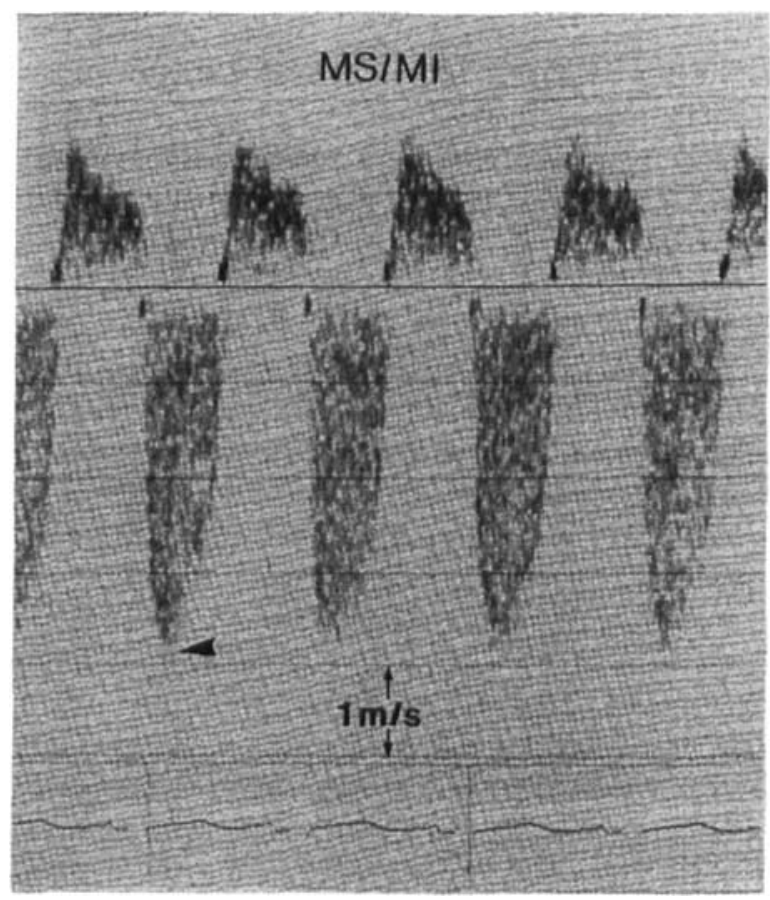

Figure 6. Continuous-wave Doppler recording from the cardiac apex of a child with mitral stenosis and insufficiency (MS/MI). The peak velocity of the MI jet (black arrow) is $3.8 \mathrm{~m} / \mathrm{sec}$. This predicts a pressure gradient of $4 \times(3.8)^{2}$ or $58 \mathrm{mmHg}$ across the mitral valve in systole. The patient's arm systolic blood pressure was $80 \mathrm{mmHg}$; therefore, left atrial peak pressure in systole is $80-58$ or $22 \mathrm{mmHg}$. 
at the cardiac apex and a two- or four-chamber view is obtained with the ultrasound beam parallel to the high velocity jet from the left ventricle into the left atrium. High velocity Doppler signals are noted throughout systole. The peak mitral regurgitant velocity $(\mathrm{V} \mathrm{mr}$ ) is used to calculate peak systolic pressure gradient between the left ventricle and the left atrium $(\mathrm{PG} / \mathrm{s} \mathrm{lv}-\mathrm{la})$ :

$$
(\mathrm{PG} / \mathrm{s} \mathrm{lv}-\mathrm{la})=4(\mathrm{~V} \mathrm{mr})^{2}
$$

If it is assumed that brachial artery systolic pressure is equivalent to left ventricular peak systolic pressure, then left atrial peak systolic pressure $(\mathrm{P} / \mathrm{s}$ la) can be calculated as the difference between brachial systolic pressure $(\mathrm{P} / \mathrm{s} \mathrm{ba})$ and the systolic pressure gradient across the mitral valve:

$$
(\mathrm{P} / \mathrm{s} \mathrm{la})=(\mathrm{P} / \mathrm{s} \mathrm{ba})-4(\mathrm{~V} \mathrm{mr})^{2}
$$

The potential errors encountered in the use of this approach are similar to those noted for left ventricular diastolic pressure calculation in the presence of aortic regurgitation. Despite these limitations, the approach can be applied to patients with cardiomyopathy and mitral stenosis. ${ }^{24}$

\section{Assessment of Ventricular Function}

\section{Ventricular Systolic Function}

Doppler echocardiography evaluates intracardiac blood flow and provides an estimate of ventricular performance that is independent of ventricular geometry. Cardiac output is one ejection phase index of function that can be calculated from the Doppler examination. Doppler-derived values for cardiac output have correlated closely with those measured invasively. ${ }^{25-28}$ Stroke volume or cardiac output can be measured for the left ventricle by using the aortic mean velocity and cross-sectional area and for the right ventricle by using the pulmonary artery mean velocity and cross-sectional area. $^{29-31}$

Catheterization and animal studies have shown that peak aortic acceleration is a good index of global left ventricular performance. ${ }^{32,33}$ Doppler echocardiography provides a noninvasive technique for the measurement of aortic peak velocity, acceleration rates and times, and deceleration rates and times. In 1983, Gardin and colleagues $^{34}$ showed that pulsed-Doppler tracings from the ascending aorta can be used to distinguish normal patients from patients with impaired systolic function (dilated cardiomyopathy patients). Peak aortic flow velocity distinguished normal subjects (mean $92 \mathrm{~cm} / \mathrm{sec}$, range 72-120) from cardiomyopathy patients (mean $47 \mathrm{~cm} / \mathrm{sec}$, range 35-62) with no overlap of data. The aortic velocity-time integral also distinguished between the two patient groups with no overlap in data (normals = mean $15.7 \mathrm{~cm}$ and range 12.6 to 22.5 ; cardiomyopathy = mean 6.7 $\mathrm{cm}$ and range 3.5 to 9.1 ). The aortic acceleration time, measured from the onset of flow to the time of the peak aortic velocity, was significantly shorter in the cardiomyopathy patients (mean $73 \mathrm{msec}$, range 55-98 $\mathrm{msec}$ ) compared to normal patients (mean 98 msec, range 83-118); however, there was considerable overlap in data between the groups. Mean aortic acceleration, calculated as peak aortic velocity divided by acceleration time, was also significantly reduced in cardiomyopathy patients (mean $659 \mathrm{~cm} / \mathrm{sec}^{2}$, range 389 to 921 ; normals = mean $955 \mathrm{~cm} / \mathrm{sec}^{2}$, range 735 to 1,318 ); but, again, there was overlap in data points for the two groups. Deceleration time (from aortic peak velocity to end of systole) and mean deceleration rate (peak aortic velocity divided by deceleration time) were lower in cardiomyopathy patients but were less useful indexes for discriminating the two patient groups.

Sabbah and colleagues ${ }^{35}$ have measured peak aortic velocity and peak acceleration rate in the ascending aorta using a continuous-wave Doppler transducer applied to the suprasternal notch. Measurements were obtained in patients at the time of cardiac catheterization. In patients with angiographic ejection fraction of $>60 \%$, peak aortic acceleration was $19 \pm 5$ $\mathrm{m} / \mathrm{sec}^{2}$. In patients with ejection fraction of $41 \%$ to $60 \%$, peak acceleration was significantly lower $\left(12 \pm 2 \mathrm{~m} / \mathrm{sec}^{2}, \mathrm{p}<.001\right)$. In patients with ejection fraction $<40 \%$, peak acceleration was lower $\left(8 \pm 2 \mathrm{~m} / \mathrm{sec}^{2}\right)$ than in patients with ejection fraction of $>60 \%(p<.001)$. An excellent correlation was found between peak aortic acceleration and ejection fraction $(r=.90)$.

In a study of open-chest dogs, Wallmeyer et $\mathrm{al}^{36}$ investigated the effects of varying preload, 
heart rate, and inotropic state on the Doppler indexes of left ventricular performance. Within a given animal, Doppler measurements of peak aortic velocity correlated closely with maximum aortic flow $(r=.96)$ and maximum aortic acceleration $(r=0.95)$, both measured with an electromagnetic flow probe around the ascending aorta. Peak aortic velocity also correlated with maximum left ventricular $\mathrm{dP} / \mathrm{dt}(\mathrm{r}=0.92)$. Doppler values for mean aortic acceleration also correlated with invasive indexes; however, there was greater interobserver variability with this Doppler parameter. The Doppler measurements of peak aortic velocity and mean aortic acceleration provided a method to assess changes in left ventricular performance under conditions of varying preload, heart rate, and inotropic state.

Aortic velocity and acceleration have been used to assess left ventricular function in patients with acute myocardial infarction. ${ }^{37,38}$ When measured within 18 hours of admission for an acute myocardial infarction, the Doppler indexes correlated closely with the patient's clinical status using the Forrester classification $^{39}$ and with subsequent survival. The Doppler indexes have also been compared to the results of exercise stress testing performed three to four weeks after acute myocardial infarction. Aortic peak velocity and acceleration and the aortic velocity-time integral were lower at peak exercise in patients with a positive exercise stress test ( $\geq 1 \mathrm{~mm}$ of ST segment depression in any lead) than those with a negative stress test.

An indirect assessment of left and right ventricular systolic performance can also be obtained by examining the shape of the Doppler velocity curves of the mitral or tricuspid insufficiency jets. ${ }^{40}$ If the rate of rise of the systolic pressure in the ventricle is impaired, then the increase in the velocity of the insufficiency jet is slower. In this case, the time from the onset of the insufficiency flow to the peak velocity of the insufficiency jet is prolonged (Fig. 1). To make this type of assessment, a clear recording of the entire Doppler envelope throughout systole is required.

\section{Ventricular Diastolic Function}

Several different indexes of left ventricular diastolic function have been derived from the mitral valve inflow Doppler. For this technique, a range-gated pulsed-Doppler examination of the left ventricular inflow tract is performed. From the apical four-chamber view, the Doppler cursor line and sample volume are placed in the mitral valve orifice at an angle as nearly parallel to flow as possible (Fig. 7). The sample volume position is adjusted to record the maximum velocity through the mitral valve. This point usually is found just distal to the anulus near the tips of the mitral valve leaflets. As discussed later, the position of the sample volume is critical in order to obtain standardized results. An adequate mitral valve Doppler examination consists of clear identification of the opening and closure points of the mitral valve and the peak velocities at rapid ventricular filling (the peak $E$ velocity) and during atrial contraction (the peak A velocity).

From the mitral valve Doppler tracing, several types of indexes of left ventricular diastolic filling can be calculated. First, diastolic time intervals reflecting the time course of relaxation can be calculated. The isovolumic relaxation time can be measured from the aortic closing component of the second heart sound to the onset of the diastolic flow velocity and requires a phonocardiogram to be recorded simultaneously with the mitral valve Doppler tracing. The isovolumic relaxation time is $75 \pm 11 \mathrm{msec}$ in normal subjects and is prolonged in patients with impaired left ventricular relaxation. ${ }^{41}$ The time from the onset of diastolic flow to the peak $\mathrm{E}$ velocity ( $\mathrm{O}$ to $\mathrm{E}$ time or $\mathrm{D}$ to $\mathrm{E}$ time) can be measured and is $100 \pm 10 \mathrm{msec}$ in normal adults. ${ }^{2}$ The duration of the early diastolic flow period can be measured from the onset of diastolic flow to the time when the Doppler curve returns from peak $\mathrm{E}$ velocity to the baseline. This time period is $214 \pm 26 \mathrm{msec}$ in normal subjects and has been reported to be prolonged in patients with left ventricular outflow obstruction. ${ }^{41,43}$ The time from the onset of diastolic flow to the point where the peak $E$ velocity falls to the value of peak E/1.4 has been measured and corresponds well with $\mathbf{M}$-mode measurements of the rapid filling period (normals $=130 \pm 20 \mathrm{msec}$ ) ${ }^{44}$ Finally, the acceleration and deceleration half-times of early diastolic rapid inflow have been used to describe the time course of relaxation. ${ }^{45}$ These time periods are measured as the intervals between the 


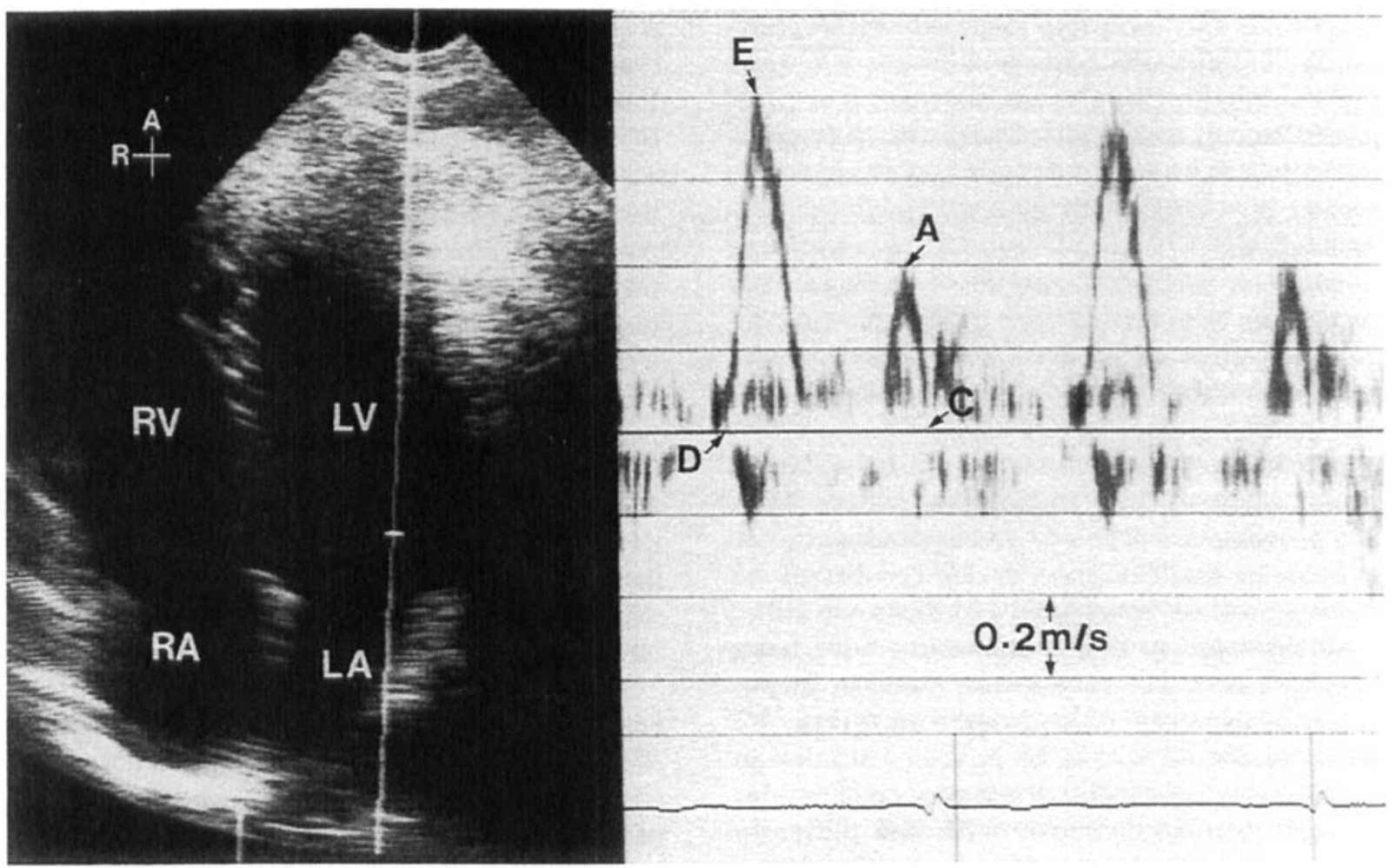

Figure 7. Technique used to record the mitral valve inflow Doppler for evaluation of diastolic flling. The apical four-chamber view (left) shows the position of the sample volume in the mitral orifice at the time of the Doppler recording. The Doppler tracing (right) shows the opening and closure points of mitral flow ( $D$ and $C$ points) and the peak velocities at rapid filling (peak $E$ ) and during atrial contraction (peak $A$ ). $A=$ anterior; $L A=$ left atrium; $R=$ right; $R A=$ right atrium; $R V=$ right ventricle.

peak $\mathrm{E}$ velocity and $50 \%$ of the peak $\mathrm{E}$ velocity on the ascending limb (acceleration half-time) and the descending limb (deceleration halftime) of early diastolic inflow.

Acceleration and deceleration half-times of the transmitral inflow velocity have been reported to be prolonged in patients with myocardial infarction (acceleration half-time $>73$ msec, deceleration half-time $>100 \mathrm{msec}$ ) compared to normal subjects (acceleration half-time $=62 \pm 18 \mathrm{msec}$, deceleration half-time $=73 \pm 24$ msec). ${ }^{45}$

A second type of diastolic parameter that has been measured from the mitral valve Doppler tracings are indexes of velocity and acceleration. The peak velocity during rapid filling or the peak $E$ velocity can be measured and is 0.60 to $0.68 \mathrm{~m} / \mathrm{sec}$ in normal adults. The peak velocity in atrial contraction or the peak $A$ velocity is
0.38 to $0.48 \mathrm{~m} / \mathrm{sec}$ in normal adults. ${ }^{42,46-48}$ The ratio of the peak $E$ to peak $A$ velocities ( $E / A$ ratio) and the ratio of the peak $A$ to peak $E$ velocities ( $\mathrm{A} / \mathrm{E}$ ratio) have been used to describe the pattern of left ventricular diastolic filling. Values for the E/A ratio in normal adults have ranged from $1.7 \pm 0.4$ to $2.5 \pm 0.9 .^{41,42,49}$ Values for the $\mathrm{A} / \mathrm{E}$ ratio in normal adults have ranged from $0.44 \pm 0.2$ to $0.66 \pm 0.2 .^{45,46,48}$ The deceleration of early diastolic flow can be measured as the slope of a straight line drawn between the peak $E$ velocity and the point where peak $E$ decreases to peak $\mathrm{E} / 2$ on the descending limb of the early diastolic inflow. In normal adults, values for the deceleration have ranged from $355 \pm 67 \mathrm{~cm} / \mathrm{sec}^{2}$ to $399 \pm 110 \mathrm{~cm} / \mathrm{sec}^{2} .46,48$

Abnormalities of the mitral valve peak velocities, velocity ratios, and deceleration rates have been reported in a number of disease 


\section{DOPPLER EVALUATION OF CARDIAC PRESSURES AND VENTRICULAR FUNCTION}

states. Kitabatake and co-workers ${ }^{46}$ found that the peak $E$ velocity and deceleration were significantly reduced in patients with hypertension, hypertrophic cardiomyopathy, and myocardial infarction. In their study, peak A velocity was significantly increased in patients with hypertension and myocardial infarction but not in patients with hypertrophic cardiomyopathy. They concluded that early diastolic filling was impaired in all three disease states and was accompanied by a compensatory increase in filling during atrial contraction in patients with hypertension and myocardial infarction. In patients with hypertrophic cardiomyopathy, the compensatory mechanism seemed to be a prolongation of rapid filling rather than an increased filling during atrial contraction. Spirito and colleagues ${ }^{41,43}$ reported similar abnormalities in a group of patients with left ventricular outflow obstruction. In the patient group, the deceleration and $\mathrm{E} / \mathrm{A}$ velocity ratio was significantly reduced compared to normal adults. Takenaka et al reported different Doppler patterns of left ventricular diastolic filling in different subgroups of patients with hypertrophic cardiomyopathy. ${ }^{48}$ In patients with hypertrophic cardiomyopathy and systolic anterior motion of the mitral valve, no significant differences were observed in peak $E$ velocity, peak $A$ velocity, $A / E$ velocity ratio, and deceleration compared to normal subjects. Patients with hypertrophic cardiomyopathy and no systolic anterior motion of the mitral valve, however, had decreased peak $E$ velocity, increased $A / E$ velocity ratio, and reduced deceleration of early diastolic flow compared to normal subjects. Mitral regurgitation was detected in all patients with systolic anterior motion of the mitral valve and in only $33 \%$ of patients without systolic anterior motion of the mitral valve. The authors postulated that increased left ventricular early diastolic filling caused by mitral regurgitation or a less extensive myopathic process reported previously to occur in patients with systolic anterior motion accounted for the differences in left ventricular diastolic filling observed in subgroups of patients with hypertrophic cardiomyopathy. In a similar study, Takenaka and co-workers compared mitral valve Doppler recordings from patients with dilated cardiomyopathy with and without mitral regurgitation to normal subjects. ${ }^{50}$ Cardiomyopathy patients without mitral regurgitation had a reduced peak $E$ velocity and an increased $\mathrm{A} / \mathrm{E}$ velocity ratio compared to normal subjects. Cardiomyopathy patients with mitral regurgitation had normal peak $E$ and peak $A$ velocities, normal A/E velocity ratio, but a shortened deceleration half-time. These findings suggest that mitral regurgitation can mask filling abnormalities on the mitral valve Doppler examination in patients with dilated cardiomyopathy.

A third type of parameter that can be measured from the mitral valve Doppler examination are indexes of peak and mean left ventricular filling rates. Rokey and colleagues compared Doppler and angiographic values for peak filling rates and half filling fraction in normal subjects and patients with coronary artery disease. ${ }^{51}$ Doppler peak filling rate was calculated as peak $\mathrm{E}$ velocity times the mitral anulus cross-sectional area (calculated as $\pi \mathrm{d}^{2} / 4$ where $\mathrm{d}=$ the anulus diameter measured from the two-dimensional echocardiogram). Normalized peak filling rate was calculated as peak filling rate divided by left ventricular end-diastolic volume (measured from the two-dimensional echocardiogram). The half filling fraction was calculated as the integral under the mitral valve Doppler tracing for the first half of diastole divided by the total velocity-time integral under the mitral valve Doppler tracing. No differences were found between Doppler and angiographic estimates of peak filling rate (296 vs $283 \mathrm{ml} / \mathrm{sec}$ ), normalized peak filling rate (1.9 vs $\left.2.0 \mathrm{sec}^{-1}\right)$, and half filling fraction ( 0.55 vs 0.55$)$. Significant correlations were found between Doppler and angiographic values for peak filling rate ( $r$ $=0.87, \mathrm{SEE}=91.5 \mathrm{ml} / \mathrm{sec}$ ) and normalized peak filling rate $\left(r=0.83, \mathrm{SEE}=0.52 \mathrm{sec}^{-1}\right)$. In general, patients with reduced angiographic peak filling rates had peak $E$ velocity often less than $0.45 \mathrm{~m} / \mathrm{sec}$ and $\mathrm{E} / \mathrm{A}$ velocity ratio of less than 1.0 .

Additional filling rates have been calculated from the mitral valve Doppler examination by Pearson and colleagues. ${ }^{49}$ These investigators calculated (1) peak atrial filling rate as the product of peak A velocity and mitral anular crosssectional area (normals $=225 \pm 72 \mathrm{ml} / \mathrm{sec}$ ), (2) 
mean filling rate as the product of mean diastolic velocity and mitral anular cross-sectional area, and (3) the rapid filling index as the quotient of peak early diastolic filling rate divided by mean filling rate (normals $=2.3 \pm 0.3$ ).

A fourth type of diastolic parameter that has been used to describe the patterns of left ventricular filling are the Doppler area fractions or filling fractions. ${ }^{44}$ The Doppler area fractions describe the percentage of the mitral valve Doppler envelope that is present in the various phases of diastole. Because the mitral valve cross-sectional area changes throughout diastole, calculation of the absolute volumetric flow that occurs in the different portions of diastole is extremely difficult. Since the volumetric flow is the product of the velocity-time integral (the integrated area under the Doppler curve) and the mitral valve cross-sectional area, approximate values for the fraction of filling of the left ventricle in the different phases of diastole are obtained by measuring several areas under the Doppler curve and dividing these areas by the total area under the Doppler curve or the total velocity-time integral (Fig. 8). Using this methodology, the area or filling fractions in the first $33 \%$ of diastole ( 0.33 area fraction) during early diastolic inflow ( $\mathrm{E}$ area fraction) and atrial con-

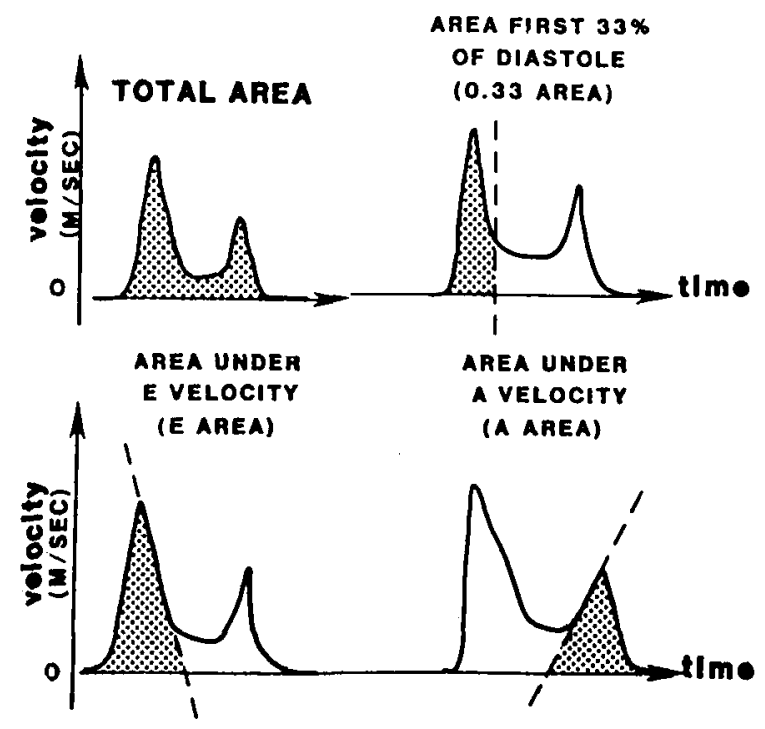

Figure 8. Diagrammatic representation of the method used to trace the various areas under the mitral valve Doppler tracing.
TABLE I

Doppler Areas and Area Fractions in Normal Adults ( $n=24)$

\begin{tabular}{ll}
\hline Doppler Areas & Normal Values \\
\hline 0.33 area & $0.076 \pm 0.020 \mathrm{~m}$ \\
0.33 area/total area & $0.53 \pm 0.062$ \\
E area & $0.086 \pm 0.018 \mathrm{~m}$ \\
E area/total area & $0.62 \pm 0.070$ \\
A area & $0.036 \pm 0.010 \mathrm{~m}$ \\
A area/total area & $0.26 \pm 0.071$ \\
E area/A area & $2.5 \pm 0.69$ \\
\hline
\end{tabular}

Values are mean \pm standard deviation.

traction (A area fraction) can be calculated. In our studies, the $\mathrm{E}$ area and $\mathrm{A}$ area were measured as the triangular portion under the Doppler curve formed by extrapolating a straight line down from the peak $E$ and peak $A$ velocities to the baseline. ${ }^{42,44,52,53}$ Other methods have been used to define the filling fractions during early and late diastolic inflow. These include dividing the Doppler curve with a straight line in the middle of the slow filling period into early and late filling fractions ${ }^{54}$ or drawing the triangular $\mathrm{E}$ area and defining all the remaining area under the Doppler curve as filling due to atrial contraction. ${ }^{55}$ Table I shows values for the Doppler area fractions obtained in our laboratory in normal adults. It is interesting that our value for the percentage of the total Doppler area occurring under the peak $E$ velocity $(0.62$ $\pm 0.07)$ is identical to Hanrath's value for the percentage of the total change in left ventricular diastolic dimension that occurs in rapid filling on the digitized $M$-mode echocardiogram(0.62 $\pm 0.10) .{ }^{56}$ Similarly, our value for the fraction of the total Doppler curve occurring under the peak $A$ velocity $(0.26 \pm 0.07)$ is very close to Hanrath's value for the percentage of total change in left ventricular dimension occurring during atrial contraction $(0.16 \pm 0.10)$.

Mitral valve Doppler area fractions have been used to detect abnormalities in left ventricular filling in a variety of disease states. ${ }^{42,44,49,52-54} \mathrm{We}$ studied left ventricular diastolic filling in a group of children with systemic hypertension and found that these children had a decreased percentage of the total Doppler area occurring 
in the first third of diastole and an increased percentage of the total Doppler area occurring under the A wave compared to age-matched normal children. ${ }^{44}$ Also, the peak A velocity was higher in the children with systemic hypertension. Diastolic filling abnormalities were detectable by mitral valve Doppler ultrasound techniques when the $\mathrm{M}$-mode indexes of diastolic function were still normal and before the development of systolic function abnormalities or left ventricular hypertrophy on the M-mode echocardiogram.

In addition, we have evaluated left ventricular diastolic filling in a group of children with hypertrophic cardiomyopathy and no mitral regurgitation using mitral valve Doppler techniques. ${ }^{52}$ These children had a decreased peak $\mathrm{E}$ velocity and a decreased percentage of the total Doppler area occurring in the first third of diastole. In these children, there was no compensatory increase in the percentage of the total Doppler area occurring during atrial contraction.

The Doppler patterns of left ventricular diastolic filling have been evaluated in a group of patients with coronary artery disease and normal global systolic function and compared with a group of age-matched normal adults. ${ }^{42}$ The coronary artery disease patients had a decreased percentage of the mitral valve Doppler area occurring during rapid filling and an increased percentage of the Doppler area occurring in late diastole suggesting that these patients have impaired left ventricular early diastolic filling. These diastolic filling abnormalities were unimproved 24 hours after successful coronary angioplasty. In children with severe left ventricular outflow obstruction, we have observed similar abnormalities in diastolic filling and similar results immediately after successful relief of the obstruction with balloon valvuloplasty or angioplasty. ${ }^{53}$

There are several limitations of the mitral valve Doppler technique that should be noted. The Doppler time intervals and peak velocities vary with cardiac cycle lengths. Peak velocities also vary with age and ventricular preload. The peak $E$ and peak $A$ velocity tend to decrease and to increase respectively with aging and the $\mathrm{A} / \mathrm{E}$ velocity ratio shows a significant increase with aging. ${ }^{47}$ Also, the peak $A$ velocity and the $\mathrm{A} / \mathrm{E}$ velocity ratio tend to be increased in the fetus in utero and in the first few days after birth. ${ }^{57}$ The position of the sample volume can alter the mitral valve Doppler tracing. Gardin and colleagues $^{58}$ compared Doppler tracings obtained from the left atrium just proximal to the mitral valve with Doppler tracings obtained at the tips of the mitral valve leaflets. These investigators found that the peak $E$ velocity was $25 \%$ lower and the peak A velocity was $22 \%$ lower in the tracings obtained from the left atrial site. The $\mathrm{A} / \mathrm{E}$ velocity ratio was the same at both sites. In addition, the mitral valve Doppler indexes vary with the phases of respiration and complexes should be measured at end-expiration to eliminate these variations. Finally, early diastolic left ventricular filling is affected not only by left ventricular relaxation properties but also by the left atrial pressure at the onset of left ventricular filling. ${ }^{59}$ Factors that increase left atrial pressure will alter left ventricular diastolic filling patterns. For example, mitral regurgitation increases left atrial pressure and causes an increase in mitral valve flow velocity, left ventricular filling rate, and mitral volumetric flow.

Little information currently is available on the use of Doppler echocardiography to assess right ventricular diastolic function. Using the tricuspid valve inflow Doppler, peak velocities during early and late diastolic filling, peak filling rates, and filling fractions of the right ventricle can be calculated. In the future, one can expect that these measurements will be used to analyze right ventricular diastolic filling in a variety of disease states.

\section{Summary}

Doppler echocardiography has had a profound influence on the clinical practice of cardiology. With the use of the modified Bernoulli equation, Doppler echocardiography provides a noninvasive technique for calculating intracardiac pressures. Compared to invasive measurements, the Doppler estimates of intracardiac pressures are accurate and reproducible. By the evaluation of intracardiac blood flow, Doppler echocardiography provides a technique for the evaluation of ventricular performance that is in- 
dependent of ventricular geometry. This application of the Doppler technique is in its infancy and much investigative work is needed to correlate the invasive and noninvasive measurements of ventricular function and to determine the effect of factors such as heart rate, loading conditions, and cardiac drugs on the Doppler indexes of function. In the future, it is very likely that Doppler color flow mapping techniques will provide additional information on ventricular emptying and filling patterns that will be important in the noninvasive assessment of cardiac function.

\section{References}

1. Hatle L, Angelsen B: Doppler Ultrasound in Cardiology. Philadelphia, Lea \& Febiger, 1985, p. 1.

2. Holen J, Aaslid R, Landmark K, et al: Determination of pressure gradient in mitral stenosis with a non-invasive ultrasound Doppler technique. Acta Med Scand 199:455, 1976.

3. Hatle L, Brubakk A, Tromsdal A, et al: Noninvasive assessment of pressure drop in mitral stenosis by Doppler ultrasound. Br Heart $J$ 40:131, 1978.

4. Stamm RB, Martin RP: Quantification of pressure gradients across stenotic valves by Doppler ultrasound. J Am Coll Cardiol 2:707, 1983.

5. Stevenson JG, Kawabori I: Noninvasive determination of pressure gradients in children: Two methods employing pulsed Doppler echocardiography. J Am Coll Cardiol 3:179, 1984.

6. Hatle L, Angelsen BA, Tromsdal A: Non-invasive assessment of aortic stenosis by Doppler ultrasound. Br Heart J 43:284, 1980.

7. Hatle L: Noninvasive assessment and differentiation of left ventricular outflow obstruction by Doppler ultrasound. Circulation 64:381, 1981.

8. Berger M, Berdoff RL, Gallerstein PE, et al: Evaluation of aortic stenosis by continuous wave Doppler ultrasound. $J$ Am Coll Cardiol 3:150, 1984.

9. Young DB, Quinones MA, Waggoner AD, et al: Diagnosis and quantification of aortic stenosis with pulsed Doppler echocardiography. Am J Cardiol 45:987, 1980.

10. Lima CO, Sahn DJ, Valdes-Cruz LM, et al: Prediction of the severity of left ventricular outflow tract obstruction by quantitative two-dimensional echocardiographic Doppler studies. Circulation 68:348, 1983.

11. Yock PG, Naasz C, Schnittger I, et al: Doppler tricuspid and pulmonic regurgitation in normals: Is it real? (Abstract) Circulation 70(Suppl II):II40, 1984.

12. Berger M, Haimowitz A, Van Tosh A, et al: Quantitative assessment of pulmonary hypertension in patients with tricuspid regurgitation using continuous wave Doppler ultrasound. $J$ Am Coll Cardiol 6:359, 1985.

13. Murphy DJ Jr, Ludomirsky A, Huhta JC: Continuous-wave Doppler in children with ventricular septal defect: Noninvasive estimation of interventricular pressure gradient. Am J Cardiol $57: 428,1986$.

14. Silbert DR, Brunson AC, Schiff R, et al: Determination of right ventricular pressure in the presence of a ventricular septal defect using continuous wave Doppler ultrasound. $J$ Am Coll Cardiol 8:379, 1986.

15. Hatle L, Angelsen B: Doppler Ultrasound in Cardiology. Philadelphia, Lea \& Febiger, 1985, p. 162.

16. Masuyama T, Kodama K, Kitabatake A, et al: Continuous-wave Doppler echocardiographic detection of pulmonary regurgitation and its application to noninvasive estimation of pulmonary artery pressure. Circulation 74:484, 1986.

17. Hatle L, Angelsen BAJ, Tromsdal A: Noninvasive estimation of pulmonary artery systolic pressure with Doppler ultrasound. $\mathrm{Br}$ Heart $J$ 45:157, 1981.

18. Kitabatake A, Inoue M, Asao M, et al: Noninva sive evaluation of pulmonary hypertension by a pulsed Doppler technique. Circulation 68:302, 1983.

19. Kosturakis D, Goldberg SJ, Allen HD, et al: Doppler echocardiographic prediction of pulmonary arterial hypertension in congenital heart disease. Am J Cardiol 53:1110, 1984.

20. Martin-Duran $\mathbf{R}$, Larman $\mathbf{M}$, Trugeda $A$, et al: Comparison of Doppler-determined elevated pulmonary arterial pressure with pressure measured at cardiac catheterization. Am J Cardiol $57: 859,1986$.

21. Matsuda M, Sekiguchi T, Sugishita Y, et al: Reliability of non-invasive estimates of pulmonary hypertension by pulsed Doppler echocardiography. Br Heart $J$ 56:158, 1986.

22. Isobe M, Yazaki Y, Takaku F, et al: Prediction of pulmonary arterial pressure in adults by pulsed Doppler echocardiography. Am J Cardiol 57:316, 1986.

23. Serwer GA, Cougle AG, Eckerd JM, et al: Factors affecting use of the Doppler-determined time from flow onset to maximal pulmonary ar- 
tery velocity for measurement of pulmonary artery pressure in children. Am $J$ Cardiol 58:352, 1986.

24. Hatle L, Angelsen B: Doppler Ultrasound in Cardiology. Philadephia, Lea \& Febiger, 1985, p. 170.

25. Colocousis JS, Huntsman LL, Curreri PW: Estimation of stroke volume changes by ultrasonic Doppler. Circulation 56:914, 1977.

26. Huntsman LL, Stewart DK, Barnes SR, et al: Noninvasive Doppler determination of cardiac output in man. Clinical validation. Circulation 67:593, 1983.

27. Alverson DC, Eldridge M, Dillon T, et al: Noninvasive pulsed Doppler determination of cardiac output in neonates and children. $J$ Pediatr 101:46, 1982.

28. Nishimura RA, Callahan MJ, Schaff HV, et al: Noninvasive measurement of cardiac output by continuous wave Doppler echocardiography: Initial experience and review of the literature. Mayo Clin Proc 59:484, 1984.

29. Goldberg SJ, Sahn DJ, Allen HD, et al: Evaluation of pulmonary and systemic blood flow by 2-dimensional Doppler echocardiography using fast Fourier transform spectral analysis. Am $J$ Cardiol 50:1394, 1982.

30. Sanders SP, Yeager S, Williams RG: Measurement of systemic and pulmonary blood flow and QP/QS ratio using Doppler and two-dimensional echocardiography. Am J Cardiol 51:952, 1983.

31. Barron JV, Sahn DJ, Valdes-Cruz LM, et al: Clinical utility of two-dimensional Doppler echocardiographic techniques for estimating pulmonary to systemic blood flow ratios in children with left to right shunting atrial septal defect, ventricular septal defect, or patent ductus arteriosus. J Am Coll Cardiol 3:169, 1984.

32. Noble MIM, Trenchard D, Guz A: Left ventricular ejection in conscious dogs, 1 . Measurement and significance of the maximum acceleration of blood from the left ventricle. Circ Res 19:139, 1966.

33. Stein PD, Sabbah HN: Ventricular performance measured during ejection. Studies in patients of the rate of change of ventricular power. $A m$ Heart $J$ 91:599, 1976.

34. Gardin JM, Iseri LT, Elkayam U, et al: Evaluation of dilated cardiomyopathy by pulsed Doppler echocardiography. Am Heart $J$ 106:1057, 1983.

35. Sabbah HN, Khaja F, Brymer JF, et al: Noninvasive evaluation of left ventricular performance based on peak aortic blood acceleration measured with a continuous-wave Doppler velocity meter. Circulation 74:323, 1986.

36. Wallmeyer K, Wann LS, Sagar KB, et al: The influence of preload and heart rate on Doppler echocardiographic indexes of left ventricular performance: Comparison with invasive indexes in an experimental preparation. Circulation 74:181, 1986.

37. Mehta N, Bennett DE: Impaired left ventricular function in acute myocardial infarction assessed by Doppler measurement of ascending aortic blood velocity and maximum acceleration. $A m J$ Cardiol 57:1052, 1986.

38. Mehta N, Bennett D, Mannering D, et al: Usefulness of noninvasive Doppler measurement of ascending aortic blood velocity and acceleration in detecting impairment of the left ventricular functional response to exercise three weeks after acute myocardial infarction. Am $J$ Cardiol 58:879, 1986.

39. Forrester JS, Diamond GA, Swan HJC: Correlative classification of clinical and hemodynamic function after acute myocardial infarction. $A m J$ Cardiol 39:137, 1977.

40. Hatle L, Angelsen B: Doppler Ultrasound in Cardiology. Philadelphia, Lea \& Febiger, 1985, p. 170.

41. Spirito P, Maron BJ, Bonow RO: Noninvasive assessment of left ventricular diastolic function: Comparative analysis of Doppler echocardiographic and radionuclide angiographic techniques. $J$ Am Coll Cardiol 7:518, 1986.

42. Wind BE, Snider AR, Buda AG, et al: Pulsed Doppler assessment of left ventricular diastolic filling in patients with coronary artery disease before and immediately after coronary angioplasty. Am J Cardiol 59:1041, 1987.

43. Spirito P, Maron BJ, Bellotti P, et al: Noninvasive assessment of left ventricular diastolic function: Comparative analysis of pulsed Doppler ultrasound and digitized M-mode echocardiography. Am J Cardiol 58:837, 1986.

44. Snider AR, Gidding SS, Rocchini AP, et al: Doppler evaluation of left ventricular diastolic filling in children with systemic hypertension. Am J Cardiol 56:921, 1985.

45. Fujii J, Yazaki Y, Sawada $\mathrm{H}$, et al: Noninvasive assessment of left and right ventricular filling in myocardial infarction with a two-dimensional Doppler echocardiographic method. J Am Coll Cardiol 5:1155, 1985.

46. Kitabatake A, Inoue $M$, Asao $M$, et al: Transmitral blood flow reflecting diastolic behavior of the 
left ventricle in health and disease: A study by pulsed Doppler technique. Jpn Circ $J$ 46:92, 1982.

47. Miyatake $\mathrm{K}$, Okamoto $\mathrm{M}$, Kinoshita $\mathrm{N}$, et al: Augmentation of atrial contribution to left ventricular inflow with aging as assessed by intracardiac Doppler flowmetry. Am J Cardiol 53:586, 1984.

48. Takenaka K, Dabestani A, Gardin J, et al: Left ventricular filling in hypertrophic cardiomyopathy: A pulsed Doppler echocardiographic study. $J$ Am Coll Cardiol 7:1263, 1986.

49. Pearson AC, Schiff M, Mrosek D, et al: Left ventricular diastolic function in weight lifters. Am J Cardiol 58:1254, 1986.

50. Takenaka AK, Dabestani A, Gardin JM, et al: Pulsed Doppler echocardiographic study of left ventricular filling in dilated cardiomyopathy. Am J Cardiol 58:143, 1986.

51. Rokey R, Kuo LC, Zoghbi WA, et al: Determination of parameters of left ventricular diastolic filling with pulsed Doppler echocardiography: Comparison with cineangiography. Circulation 71:543, 1985.

52. Gidding SS, Snider AR, Rocchini AP, et al: Left ventricular diastolic filling in children with hypertrophic cardiomyopathy: Assessment with pulsed Doppler echocardiography. J Am Coll Cardiol 8:310, 1986.
53. Shaffer EM, Snider AR, Rocchini AP, et al: Diastolic filling in LV outflow obstruction pre and post balloon angioplasty. (Abstract) $J \mathrm{Am}$ Coll Cardiol 9(Suppl A):130A, 1987.

54. Friedman BJ, Drinkovic N, Miles H, et al: Assessment of left ventricular diastolic function: Comparison of Doppler echocardiography with gated blood pool scintigraphy. J Am Coll Cardiol 8:1348, 1986.

55. Plehn JF: Personal communication, April 1987.

56. Hanrath $P$, Mathey DG, Siegart $R$, et al: Left ventricular relaxation and filling pattern in different forms of left ventricular hypertrophy: An echocardiographic study. Am $J$ Cardiol 45:15, 1980.

57. Reed KL, Sahn DJ, Scagnelli S, et al: Doppler echocardiographic studies of diastolic function in the human fetal heart: Changes during gestation. J Am Coll Cardiol 8:391, 1986.

58. Gardin JM, Dabestani A, Takenaka K, et al: Effect of imaging view and sample volume location on evaluation of mitral flow velocity by pulsed Doppler echocardiography. Am J Cardiol 57:1335, 1986.

59. Ishida Y, Meisner JS, Tsujioka K, et al: Left ventricular filling dynamics: influence of left ventricular relaxation and left atrial pressure. Circulation 74:187, 1986. 